\title{
LEPTOSPIROSIS IN CHILDREN: A REVIEW FOR FAMILY PHYSICIANS
}

\author{
MILIND S. TULLU, SUNIL KARANDE 1
}

\begin{abstract}
Leptospirosis is an important cause of acute febrile illness in the monsoon season in India. It is a zoonotic disease that is spread primarily by rodents. There exist two clinical types: anicteric and icteric leptospirosis. Both have an initial septicemic phase followed by an immune phase. The clinical manifestations vary and the disease manifestations may range from a nonspecific febrile illness to one with severe multiorgan failure. Weil's disease is the severe form of the infection; which occurs in less than $10 \%$ of the patients and is associated with high mortality. The methods available for diagnosis and treatment of leptospirosis are discussed in this review. Crystalline penicillin is the drug of choice for treatment of leptospirosis in children. Avoidance of contact with flood waters and rodent control are vital for prevention of the disease. We also discuss the differences between childhood leptospirosis and adult disease. We used two methods to garner the information presented in this article: i) we searched the PubMed database (http:// ww w. ncbi.nlm.nih.gov/ pubmed/) using the keywords 'leptospirosis' and 'children,' with special emphasis given to articles from the Indian literature; and ii) we reviewed the chapters on leptospirosis in the standard textbooks of pediatric and infectious diseases.
\end{abstract}

Key words: Icteric, immune, jaundice, leptospirosis, liver, penicillin, renal, rodents, septicemic

DOI: $10.4103 / 0019-5359.55893$

\section{INTRODUCTION}

Leptospirosis, a zoonotic disease of worldwide distribution, has become an important cause of acute febrile illness in children in India during the monsoon and immediate post-monsoon

Department of Pediatrics, Seth G.S. Medical College and KEM Hospital, Mumbai 400012, 'Department of Pediatrics, L.T.M. Medical College and LTMG Hospital, Sion, Mumbai-400 022, India.

\section{Correspondence:}

Dr Milind S Tullu

'Sankalp Siddhi,' Block No.1,

Ground Floor, Kher Nagar, Service Road,

Bandra (East), Mumbai-400 051, Maharashtra, India.

E-mail: milindtullu@vsnl.net periods. In recent times, it has also become common to encounter cases of leptospirosis throughout the year in urban areas due to poor sanitation, water logging, overcrowding, and mushrooming of slums. Most human cases of leptospirosis have been reported from the tropical and subtropical developing countries. ${ }^{[1]}$ Though Weil described the condition in 1886, the causal agent was identified only in $1915 .^{[2-5]}$

\section{EPIDEMIOLOGY}

Leptospira infect many species of animals, including dogs, cats, livestock, and birds; 
however, the rat (Rattus norwegicus) is the main source of human infection. ${ }^{[1-3]}$ Infected animals excrete spirochetes in urine for several weeks, ${ }^{[1-3]}$ as the organisms can remain in the convoluted tubules of the kidneys of host animals for long periods. ${ }^{[2-4]}$ The majority of human cases worldwide result from occupational exposure to water (or flood waters) or soil contaminated with rat urine..$^{[1-9]}$ Occupational groups with a relatively higher incidence of this disease include farmers, agricultural workers, veterinarians, animal handlers, rodent control workers, laboratory workers, and those exposed to flood waters. ${ }^{[1-5,10,11]}$ The disease is more common in the working-age population (15-64 years) ${ }^{[11]}$ Leptospira can be isolated from cultures of infected soil for up to 6 weeks. ${ }^{[2]}$ However, leptospira cannot survive desiccation or salt water ${ }^{[3]}$ In children, the risk factors for acquiring the disease include school-going age, exposure to flood waters, contact of bare feet with mud, wading through river, and contact with domestic animals. ${ }^{[12,13]}$

There have been many recent reports on the seroprevalence and the clinical spectrum of the disease (including mild disease in children) from Indonesia, Vietnam, and Cambodia. ${ }^{[12,14-17]}$ In a study (from Cambodia), only 6 of 202 (i.e., 3\%) cases of acute hemorrhagic fever in the study population (which included all age-groups) could be attributed to leptospiral infection. ${ }^{[14]}$ In another study on primary school children from Binh Thuan province (Vietnam), the authors found that though frequently exposed to leptospira (as demonstrated by the seroprevalence of $11 \%$ at the age of 7 years), the incidence of reported symptomatic leptospirosis was low in these children. ${ }^{[12]}$
The disease has been endemic in the Indian states of Kerala, Tamil Nadu, and the Andamans. Also, with improvement in diagnostic facilities over the past few years, leptospirosis is being reported from almost all the cities and states of India, including Delhi, Mumbai, Uttar Pradesh, Orissa, and Gujarat. ${ }^{[3,6]}$ Thirty out of $93(32 \%)$ urban slum children from Mumbai admitted for suspected leptospirosis (during the period July-August 2001) were confirmed to have acute leptospirosis after investigations. ${ }^{[6]}$ Periods of heavy rain followed by days of little or no rain seem to be the setting for leptospirosis epidemics in Kerala (India), suggesting that leptospira multiply in the walking paths where water remains undrained for a period of 2-3 days after the rains and provide the source for most of the infections. ${ }^{[7]}$ Cases of leptospirosis have been reported from Mumbai from the year 1999-2000 onwards, and concurrent outbreaks of leptospirosis and dengue have been shown to have occurred in the slums of Mumbai city. ${ }^{[6,18,19]}$

The exact seropositivity rates for leptospirosis in Indian children are not known, though periodic outbreaks are known to occur. In a study by Kalita et al., $22.57 \%$ adults with pyrexia of unknown origin (total 536 cases of fever) in a hospital in Guwahati (Assam, India) were found to be positive for leptospirosis, with the seropositivity being higher among individuals having contact with animals and in those working in the forest areas and floodaffected areas. ${ }^{[20]}$ On the other hand, in an outbreak of leptospirosis in Peddamandem Mandal, Chittoor district (Andhra Pradesh, India) in 2005, 49 out of 86 (56.97\%) single sera samples of suspected cases (all adults) from seven villages were found to be positive 
for leptospirosis. ${ }^{[21]}$ In a larger study (involving 67,013 suspected cases) from Tamil Nadu (South India), the seropositivity rate was as high as $57.55 \%$ between $1997-2006 .{ }^{\text {[22] }}$ The seropositivity in children $<5$ years, $5-10$ years, 10-20 years, 20-40 years adults, and $>40$ years adults was seen to be $11.41 \%, 12.11 \%$, $18.16 \%, 40.16 \%$, and $18.16 \%$, respectively, in males (859 cases) and $11.25 \%, 11.56 \%$, $17.19 \%, 34.84 \%$, and $25.16 \%$, respectively, in females (640 cases) during the period from October to December 2004. ${ }^{[22]}$ Swapna et al. (Calicut, Kerala, India) have shown the seroprevalence to be $38.1 \%$ (in patients $10-60$ years of age) in the high-risk group (agricultural workers, fishermen, hospital sanitary workers, sewage workers, laboratory staff, veterinarians, and construction workers) vs $24 \%$ in healthy controls (students and blood donors). ${ }^{[23]}$

\section{ETIOLOGY AND PATHOGENESIS}

Leptospirosis is caused by spirochetes of the genus Leptospira and is the most widespread zoonosis in the world. ${ }^{[1,4]}$ Leptospira are finely coiled filamentous aerobic spirochetes that can be visualized by dark-field microscopy. ${ }^{[1,3]}$ Pathogenic leptospira have historically been classified as Leptospira interrogans and include $>200$ distinct serovars. ${ }^{[1,2]}$ Common Indian serovars include autumnalis, australis, batavia, canicola, copenhagni, cynopteri, grippotyphosa, hardjo, icterohaemorrhagiae, javanica, patoc, pomona, pyrogenes, ratnapura, and valbuzzi. ${ }^{[5,22-33]}$ Leptospires enter the human body through abrasions and cuts in the skin or through intact mucous membrane (conjunctiva, nasopharynx, and vagina); occasionally, the entry may be via intact soggy skin that has been exposed to water for prolonged period. ${ }^{[1-4]}$ Post penetration, they circulate in the bloodstream and spread to other organs. ${ }^{[1-3]}$ The primary lesion is damage to the endothelial lining of small blood vessels, which results in ischemic damage to the concerned organ (e.g., the liver, kidneys, meninges, and muscles). ${ }^{[1-4]}$ The pathogenicity of leptospira results from the enzymes, toxins, or metabolites elaborated by or released from the lysed organisms. ${ }^{[2]}$ In severe cases, petechiae and ecchymosis are seen in various internal organs at postmortem examination. ${ }^{[3,5,34]}$ Degenerative changes, with hypertrophy and hyperplasia of Kupffer cells in the liver, diffuse tubulointerstitial inflammation and tubular necrosis in the kidneys, and congestion with focal hemorrhages in the lungs, are the main histopathological features. . $^{[3,5,13,34]}$

\section{CLINICAL FEATURES}

Most patients have subclinical or very mild illness. ${ }^{[1,5,10]}$ The exact ratio of asymptomatic to symptomatic leptospirosis in children (from India) is not available as most of the infections are either subclinical or have nonspecific manifestations, indistinguishable from that of other common febrile illnesses. In a study from the Andaman and Nicobar islands (India), 90\% of school children had subclinical or unnoticed infections. ${ }^{[35]}$ It was also seen that children who had had the infection earlier (i.e., were previously seropositive) suffered less morbidity and mortality in subsequent outbreaks. ${ }^{[35]}$ The clinical presentation of leptospirosis varies widely; it can range from an acute febrile illness to a severe syndrome of multiorgan dysfunction and therefore the diagnosis may be missed unless the physician has a high index of suspicion for the disease..$^{[1,2,9]}$ Symptomatic infection presents as a sudden-onset febrile 
illness with nonspecific signs and symptoms $(70 \%)$ or as aseptic meningitis $(20 \%)$ or hepatorenal dysfunction (10\%). ${ }^{[1,2,36]}$ Both anicteric (90\% or more cases) and icteric leptospirosis are known to occur. ${ }^{[1-6,8]}$ The more common, mild, anicteric form of the disease is characterized by nonspecific symptoms such as fever, headache, chills, myalgia, nausea, and abdominal pain, while the severe, potentially fatal, icteric form of leptospirosis (Weil's syndrome) is characterized by renal, hepatic, and vascular complications. ${ }^{[5,10]}$

According to information provided by the World Health Organization, the disease can present in one of four ways ${ }^{[37,38]}$ :

(i) As a mild influenza-like illness

(ii) As Weil's syndrome, characterized by jaundice, renal failure, hemorrhage, and myocarditis with arrhythmias

(iii) As meningitis/meningoencephalitis

(iv) As pulmonary hemorrhage with respiratory failure

The Indian Leptospirosis Society's criteria for clinically suspecting leptospirosis is also very useful. ${ }^{[6,39]}$ According to these criteria, leptospirosis should be suspected in a child presenting with a history of abrupt onset of high fever $\left(>39^{\circ} \mathrm{C}\right)$ and bodyache/headache, with any one or more of the following features: i) jaundice, ii) oliguria, iii) cough and breathlessness, iv) hemorrhagic tendency, and $v$ ) signs of meningeal irritation or altered sensorium or convulsions. ${ }^{[6,39]}$

The clinical presentation of leptospirosis is characteristically biphasic. ${ }^{[1-3]}$ After an incubation period of about 7-12 days (range 2-20 days), the first stage or the septicemic phase occurs; during this phase leptospira can be isolated from the blood, cerebrospinal fluid (CSF), and other tissues. ${ }^{[1,2,4,5]}$ The initial symptoms may last for up to a week..$^{[1,2]}$ This is followed by a brief period of well-being before the onset of the symptomatic second stage or the immune phase..$^{[1,2]}$ The immune (or leptospiruric) phase is characterized by the disappearance of organisms from the blood and CSF and the appearance of circulating antibody. ${ }^{[1,2]}$ Despite the presence of circulating antibodies, the organisms may persist in the kidney, the urine (for 1-4 weeks), and aqueous humor. ${ }^{[1,2]}$ This phase may last for several weeks (4-30 days). ${ }^{[1,2]}$

\section{Anicteric leptospirosis}

The septicemic phase (which lasts for 3-7 days) has an abrupt onset, with fever, chills, severe headache, malaise, lethargy, nausea, vomiting, and severe myalgia. ${ }^{[1-6]}$ Some children may have bradycardia and hypotension, but circulatory collapse is uncommon and death is extremely rare during this phase. ${ }^{[1,2]}$ Extreme muscle tenderness (most prominent in the lower limbs, lumbosacral spine, cervical region, and abdomen); conjunctival suffusion, with photophobia and orbital pain (but without chemosis or purulent exudate); lymphadenopathy; and hepatosplenomegaly may also be seen. ${ }^{[1-6]} A$ transient truncal erythematous maculopapular rash lasting for about a day may occur in a few cases. ${ }^{[1-3]}$ Uncommon manifestations include pharyngitis, pneumonitis/hemoptysis, cholecystitis, arthralgia/arthritis, and carditis. ${ }^{[1,2,40]}$ Some patients may remain asymptomatic after this phase. ${ }^{[2]}$ The immune phase (which lasts for up to 30 days) may follow a brief asymptomatic period of 2-3 days, 
and manifests with recurrence of fever (of $100-105^{\circ} \mathrm{F}$ ) and signs of aseptic meningitis; the patient may have intense headache and retrobulbar pain. ${ }^{[1-4]}$ An abnormal CSF profile is seen in $80 \%$ of infected children; CSF findings include elevated pressure, pleocytosis of up to 500 cells $/ \mathrm{mm}^{3}$ (with neutrophils initially, followed by mononuclear predominance), normal or slightly elevated proteins (up to $300 \mathrm{mg} / \mathrm{dl}$ ), and normal glucose values; however, only $50 \%$ of cases have meningeal manifestations. ${ }^{[1-5,36]}$ It is uncommon to have encephalitis, seizures, cranial/ peripheral neuropathies, myelitis, radiculitis, papilledema, or paralysis. ${ }^{[1-4]}$ However, it is important to remember these varying clinical manifestations of neuroleptospirosis to avoid confusing the disease with cerebral malaria, dengue fever, tuberculous meningitis, hepatic encephalopathy, viral encephalitis, etc. ${ }^{[41]}$ Alteration of sensorium is more common in children than in adults. ${ }^{[13]} A$ self-limiting uveitis may occur and may rarely result in permanent visual impairment. ${ }^{[1-3,5]}$ Restlessness, mood disturbances, mild alterations of sensorium, anorexia, nausea, vomiting, abdominal pain, and constipation or diarrhea may be seen in both stages of anicteric disease. [2] Leukocytosis or leukopenia, neutrophilia, and anemia may occur and an elevated erythrocyte sedimentation rate is the rule. ${ }^{[2,3]}$

\section{Icteric leptospirosis (Weil's syndrome)}

This is a severe form of the infection and occurs in $<10 \%$ of patients. ${ }^{[1-3,5]}$ It is more often seen in patients older than 30 years and is less common in children. ${ }^{[1]}$ The initial features (the septicemic stage) are similar to that in the anicteric illness and lasts for 3-7 days. ${ }^{[1-4]}$ The immune phase is characterized by clinical and laboratory evidence of hepatic and renal dysfunction and lasts for 10-30 days. ${ }^{[1-5]}$ In severe cases, hemorrhagic manifestations and cardiovascular shock also occur. ${ }^{[1]}$ Hepatic abnormalities include hepatomegaly, right upper quadrant pain, direct and indirect hyperbilirubinemia, elevation of alkaline phosphatase, hypoprothrombinemia, hypoalbuminemia, modest elevation of serum hepatic transaminases, and acalculous cholecystitis. ${ }^{[1-5,42]}$ The jaundice (serum total bilirubin is usually $<20 \mathrm{mg} / \mathrm{dl}$ ) is due to hepatocellular injury and not hepatocellular necrosis (the liver function usually returns to normal after recovery); a hemolytic process can be documented in only a few patients. ${ }^{[1,2]}$ Hepatic dysfunction (though not directly responsible for mortality) is present in most patients who die, and a fatal outcome is rare in the absence of hepatic dysfunction. ${ }^{[2]}$ Renal manifestations are common, with abnormal urine analysis (hematuria, proteinuria, and hyaline and granular casts) and azotemia, which is often associated with oliguria/anuria (an ominous sign). ${ }^{[1-5]}$ Acute renal failure occurs in up to $16-40 \%$ of cases and is the commonest cause of mortality. ${ }^{[1,2]}$ Nonspecific abnormalities in the electrocardiogram are common (being present in $90 \%$ of patients) but congestive cardiac failure is uncommon. ${ }^{[1-4]}$ Hemorrhagic manifestations (epistaxis, hemoptysis, and gastrointestinal/adrenal hemorrhage) rarely occur. ${ }^{[1-5]}$ Thrombocytopenia occurs in over half the pediatric patients; it is transient and is not due to disseminated intravascular coagulation but it is significantly associated with renal failure..$^{[1,3]}$ Both acute renal failure and jaundice (i.e., Weil's syndrome) are less common in children than in adults. ${ }^{[13]}$ The mortality rate is 
about $5-15 \%$ in Weil's syndrome in children (which is less than that in adults). ${ }^{[1,2,5]}$

\section{DIFFERENTIAL DIAGNOSIS}

Leptospirosis should be considered in all patients with acute febrile illness when there is a history of contact with animals or with soil/water contaminated with animal urine. ${ }^{[1,3]}$ A confirmed case of leptospirosis is one where the clinical specimens are culture positive for leptospira or the clinical symptoms are compatible with the disease and there is seroconversion or a fourfold rise in microscopic agglutination titer between acute and convalescent sera (taken at least 2 weeks apart and studied in same laboratory). ${ }^{[2]}$ A presumptive case is one where the clinical symptoms are compatible with the disease and microscopic agglutination titer is $1: 100$ or greater, there is a positive macroscopic agglutination slide test reaction on a single serum specimen obtained after onset of the symptoms, or there is a stable microscopic agglutination titer of $1: 100$ or more in two or more serum specimens obtained after onset of symptoms. ${ }^{[2]}$

Though Faine's criteria are available for diagnosis of leptospirosis in adults, these need to be studied further in the Indian context, especially in children. ${ }^{[3]} \mathrm{A}$ high index of suspicion is required for the diagnosis when a patient presents with fever, headache, and myalgia. ${ }^{[3]}$ The differential diagnosis in the first few days of the illness includes conditions like malaria, enteric fever, viral fevers, viral hepatitis, dengue fever, meningitis/encephalitis, and septicemia. ${ }^{[3,4,8,36]}$

\section{INVESTIGATIONS}

The initial investigations to be done in an acutely febrile child suspected to have leptospirosis include hemoglobin level, packed cell volume, complete blood counts with differential leukocyte count, platelet counts, peripheral smear for malarial parasites, liver transaminases, and blood culture. Serological tests for leptospirosis are done if more than $4-5$ days have elapsed since the onset of fever as it takes that much time for antibodies to start developing. ${ }^{[3,43]}$

For the specific diagnosis of leptospirosis the following tests are available:Serological tests: Serologic testing is mostly used for diagnosis. ${ }^{[1,3,44]}$ Enzyme-linked immunosorbent assay (ELISA) for detection of IgM antibodies (which is positive from the fifth day of illness onwards) and IgM-specific dot-ELISA tests are now recommended in clinical practice; these tests have a sensitivity $>80-90 \%$ and are done at many regular pathological and microbiological laboratories. ${ }^{[1-5,45-47]}$ The slide agglutination method, Dri-Dot assay, LEPTO Dipstick, latex agglutination, complement fixation assay, indirect immunofluorescent test, and indirect hemagglutination test are also available; these tests too have good sensitivity of up to $85 \%$. $^{[2,3,5,43,44,46-49]}$ However, the microscopic agglutination test (MAT) (serogroup-specific assay) using live antigen suspension of leptospiral serovars is the reference method. ${ }^{[1,44,46]}$ This test is available only in a few research institutes and is not helpful for diagnosing leptospirosis during the acute illness; however, it remains important for epidemiological research purposes. ${ }^{[1-3,45]}$ 
The test is read by dark-field microscopy for agglutination and the titers are determined; a four-fold or greater increase in titer in paired sera is confirmative. ${ }^{[1,3]}$ Agglutinins usually appear by the $12^{\text {th }}$ day of illness and reach the maximum titer by the $3^{\text {rd }}$ week. ${ }^{[1,2]}$

Demonstration of the organism and cultures: Though not commonly employed in routine practice, demonstration of the organisms in the patient's blood and culture of the organism can be used for diagnosis before the $10^{\text {th }}$ day of the illness. ${ }^{[3]}$ Spirochetes can be demonstrated by phase-contrast or dark-field microscopy but these are not very sensitive tests. ${ }^{[1,3-5]}$ Leptospira are easily cultured on media containing rabbit serum or bovine serum albumin and long-chain fatty acids. ${ }^{[1,2]}$ Leptospira can be recovered from the blood or CSF during the first 10 days of illness and from the urine after 14 days..$^{[1,2,3]}$

Detection of DNA: DNA hybridization techniques or nucleic acid amplification procedures, including polymerase chain reaction (PCR), can be used to detect the presence of leptospira in body fluids or culture supernatants. ${ }^{[2,3,5,50,51]}$

\section{TREATMENT}

In our country, a child with an acute febrile illness may often have to be empirically treated for malaria while the results of investigations are being awaited, as coinfection with malaria and leptospirosis is known to occur. ${ }^{[52-55]}$ Careful attention needs to be paid to the hydration status of the patient and the cardiac function must be monitored. Antipyretics (give paracetamol, avoid aspirin) can be used for controlling the fever. Any evidence of hemodynamic instability or hemorrhagic manifestations is an indication for transferring the patient to a pediatric intensive care unit. Intravenous fluids are required during the initial acute phase when the child is very sick and is not able to feed adequately.

Antibiotic administration (especially before the $7^{\text {th }}$ day of illness) reduces length of hospitalization and leptospiruria. ${ }^{[1,13]}$ In children, even late institution of antibiotic treatment has been shown to reduce the extent of acute renal failure and thrombocytopenia. ${ }^{[13]}$ Treatment with penicillin or tetracycline (in children $>9$ years of age) should be instituted as soon as the diagnosis is suspected. ${ }^{[1-6,36,42,51,56]}$ It has been shown that treatment within one week of onset of fever can shorten the clinical course and decrease the severity of the infection. ${ }^{[1,2,57]}$ Parenteral penicillin $G$ (6-8 million $\mathrm{U} / \mathrm{m}^{2} /$ day given intravenously in divided doses every 4 hours for 7 days) is the drug of choice. ${ }^{[1,2]}$ Tetracycline (10-20 mg/kg/ day given orally or intravenously in divided doses every 6 hours for 7 days) can be used in those allergic to penicillin. ${ }^{[1,2,5,42]}$ Doxycycline has been successfully used in adults. ${ }^{[3-5,51]}$ Oral amoxicillin (25-50 mg/kg/day in two or three divided doses) is an alternative therapy for children $<9$ years of age. ${ }^{[1,3,42]}$ Although ciprofloxacin has been occasionally used for treatment (especially in patients with uveitis), there is a need for more trials to evaluate its efficacy in both adults and children. ${ }^{\text {51,58] }}$

Adequate attention to supportive care, including maintenance of the fluid-electrolyte balance, treatment of cardiovascular collapse, and provision of dialysis for renal failure, are equally 
important. $^{[2-4,42,54]}$ Frequent monitoring of vital parameters and hemodynamic assessment, careful charting of fluid input and output, and prompt use of ionotropes (in patients with hypotension refractory to fluid therapy) are important considerations in the management of the disease.

\section{PREVENTION}

Important measures for prevention are rodent control and avoidance of contact with contaminated water and soil. . $^{[1,2,5,6]}$ Parents should instruct children not to wade through flood waters or play in puddles/stagnant water. Immunization of livestock (cattle, sheep, pigs, and horses) and family pets (cats and dogs) has been recommended as a means of eliminating some of the animal reservoirs. ${ }^{[1,2]}$ Doxycycline (200 mg orally once a week) is used as prophylaxis in adults traveling to a highly endemic area for a limited period of time and also during outbreaks, but its use in children has not been studied..$^{[1,3-5,51,59]}$

\section{PROGNOSIS}

Prognosis is determined by the severity of the illness, promptness with which the diagnosis is made, and the presence of complications such as renal failure, oliguria, thrombocytopenia, cardiac failure with hypotension and arrhythmias, respiratory failure, neurologic manifestations (including deep altered sensorium), gastrointestinal bleeding, and concomitant medical illnesses. [3,13,41,42,60-62] Recently, an unusual case of leptospirosis (following exposure to flood waters) has been described in a 19-monthold male child who presented with meningitis and acute renal failure (without jaundice) and survived the disease. ${ }^{[63]}$ Anicteric illness has good prognosis (with very occasional mortality due to myocarditis and fatal pulmonary hemorrhage). ${ }^{[3]}$ Patients with Weil's disease have mortality rates of up to $15 \% \cdot .^{[1-4,14]}$ Adults, especially those in the older age-groups, have higher mortality; also, adult survivors have longer hospital stays than children. ${ }^{[3,64]}$

\section{ACKNOWLEDGEMENT}

The authors thank Dr. Sanjay Oak- Director (Medical Education \& Major Hospitals, Municipal Corporation of Greater Mumbai) \& Dean of Seth G.S. Medical College and K.E.M. Hospital for granting permission to publish this manuscript.

\section{REFERENCES}

1. Azimi P. Leptospira. In: Kliegman RM, Jenson HB, Behrman RE, Stanton BF, editors. Nelson textbook of pediatrics. $18^{\text {th }}$ ed. Vol. 1. Philadelphia: Saunders (Elsevier): 2007. p. 1271-2.

2. Feigin RD. Leptospirosis. In: Feigin RD, Cherry JD, Demmler GJ, Kaplan SL, editors. Textbook of pediatric infectious diseases. $5^{\text {th }}$ ed. Vol. 2. Philadelphia, Pennsylvania (USA): Saunders (Elsevier): 2004. p. 1708-22.

3. Dutta TK, Christopher M. Leptospirosis- An overview. J Assoc Physicians India 2005;53: 545-51.

4. Lomar AV, Diament D, Torres JR. Leptospirosis in Latin America. Infect Dis Clin North Am 2000;14:23-39.

5. Rao RS, Gupta N, Bhalla P, Agarwal SK. Leptospirosis in India and the rest of the world. Brazilian J Infect Dis 2003;7:178-93.

6. Karande S, Kulkarni H, Kulkarni M, De A, Varaiya A. Leptospirosis in children in Mumbai slums. 
Indian J Pediatr 2002;69:855-8.

7. Pappachan MJ, Sheela M, Aravindan KP. Relation of rainfall pattern and epidemic leptospirosis in the Indian state of Kerala. J Epidemiol Community Health 2004;58:1054.

8. Karande S, Bhatt M, Kelkar A, Kulkarni M, De A, Varaiya A. An observational study to detect leptospirosis in Mumbai, India, 2000. Arch Dis Child 2003;88:1070-5.

9. Romero EC, da Motta Bernardo CC, Yasuda $\mathrm{PH}$. Human leptospirosis: A twenty-nine-year serological study in São Paulo, Brazil. Rev Inst Med Trop S Paulo 2003;45:245-8.

10. Ashford DA, Kaiser RM, Spiegel RA, Perkins BA, Weyant RS, Bragg SL, et al. Asymptomatic infection and risk factors for leptospirosis in Nicaragua. Am J Trop Med Hyg 2000;63:249-54.

11. Ciceroni L, Stepan E, Pinto A, Pizzocaro P, Dettori G, Franzin L, et al. Epidemiological trend of human leptospirosis in Italy between 1994 and 1996. Eur J Epidemiol 2000;16:79-86.

12. Thai KT, Binh TQ, Giao PT, Phuong HL, Hung $L Q$, Van Nam N, et al. Seroepidemiology of leptospirosis in southern Vietnamese children. Trop Med Int Health 2006;11:738-45.

13. Abdulkader RC, Silva MV. The kidney in leptospirosis. Pediatr Nephrol 2008;23:2111-20.

14. Laras K, Van CB, Bounlu K, Tien NT, Olson JG, Thongchanh ST, et al. The importance of leptospirosis in Southeast Asia. Am J Trop Med Hyg 2002;67:278-86.

15. Thai KT, Nga TT, Phuong HL, Giao PT, Hung le Q, Binh TQ, et al. Seroepidemiology and serological follow-up of anti-leptospiral IgG in children in Southern Vietnam. Acta Trop 2008;106:128-31.

16. Van CT, Thuy NT, San NH, Hien TT, Baranton $G$, Perolat P. Human leptospirosis in the Mekong delta, Vietnam. Trans R Soc Trop Med Hyg 1998;92:625-8.

17. Wagenaar JF, Falke TH, Nam NV, Binh TQ, Smits HL, Cobelens FG, et al. Rapid serological assays for leptospirosis are of limited value in southern Vietnam. Ann Trop Med Parasitol 2004;98:
843-50.

18. Karande S, Gandhi D, Kulkarni M, Bharadwaj R, Pol S, Thakare J, et al. Concurrent outbreak of leptospirosis and dengue in Mumbai, India, 2002. J Trop Pediatr 2005;51:174-81.

19. Shah I, Warke S, Deshmukh CT, Kamat JR. Leptospirosis: An under-diagnosed clinical condition. J Postgrad Med 1999;45:93-4.

20. Kalita JB, Rahman H. Leptospirosis among patients with pyrexia of unknown origin in a hospital in Guwahati, Assam. Indian J Public Health 2008;52:107-9.

21. Sohan L, Shyamal B, Kumar TS, Malini M, Ravi $\mathrm{K}$, Venkatesh V, et al. Studies on leptospirosis outbreaks in Peddamandem Mandal of Chittoor district, Andhra Pradesh. J Commun Dis 2008;40:127-32.

22. Koteeswaran A. Seropravalence of leptospirosis in man and animals in Tamil Nadu. Indian J Med Microbiol 2006;24:329-31.

23. Swapna RN, Tuteja U, Nair L, Sudarsana J. Seroprevalence of leptospirosis in high risk groups in Calicut, North Kerala, India. Indian J Med Microbiol 2006;24:349-52.

24. Ramadass $P$, Latha $D$, Senthilkumar A, Srinivasan $P$, Saranya N. Arbitrarily primed PCR-A rapid and simple method for typing of leptospiral serovars. Indian J Med Microbiol 2002;20:25-8.

25. Ambekar AN, Bharadwaj RS, Joshi SA, Kagal AS, Bal AM. Sero surveillance of leptospirosis among sewer workers in Pune. Indian J Public Health 2004;48:27-9.

26. Chidambaram N, Ramanathan M, Anandi V, Sasikala S, Innocent DJ, Sarayu L. Leptospirosis: Clinical presentation and correlation with serovars. J Commun Dis 2007;39:105-8.

27. Natarajaseenivasan K, Vijayachari P, Sharma S, Roy S, Sugunan AP, Biswas D, et al. Phylogenetic relatedness among leptospiral strains belonging to same serovar recovered from patients with different clinical syndromes. Infect Genet Evol 2005;5:185-91.

28. Sharma KK, Gururajkumar A, Mohan A, Sivakumar 
V, Kalawat U. A preliminary study on the prevalence of leptospira serovars among suspected cases of leptospirosis at Tirupati, Andhra Pradesh. Indian J Med Microbiol 2006;24:302.

29. Bal AM, Bharadwaj RS, Joshi SA, Kagal AS, Arjunwadkar VP. Common infecting leptospiral serovars in and around Pune, Maharashtra. Indian J Med Res 2002;115:14-6.

30. Bharadwaj R, Bal AM, Joshi SA, Kagal A, Pol SS, Garad G, et al. An urban outbreak of leptospirosis in Mumbai, India. Jpn J Infect Dis 2002;55:194-6.

31. Chaudhry R, Premlatha MM, Mohanty S, Dhawan B, Singh KK, Dey AB. Emerging leptospirosis, North India. Emerg Infect Dis 2002;8:1526-7.

32. Sethi S, Sood A, Pooja, Sharma S, Sengupta C, Sharma M. Leptospirosis in northern India: A clinical and serological study. Southeast Asian J Trop Med Public Health 2003;34:822-5.

33. Vijayachari P, Sugunan AP, Sharma S, Roy S, Natarajaseenivasan K, Sehgal SC. Leptospirosis in the Andaman Islands, India. Trans R Soc Trop Med Hyg 2008;102:117-22.

34. Salkade HP, Divate S, Deshpande JR, Kawishwar V, Chaturvedi R, Kandalkar BM, et al. A study of autopsy findings in 62 cases of leptospirosis in a metropolitan city in India. J Postgrad Med 2005;51:169-73.

35. Vijayachari P, Sugunan AP, Murhekar MV, Sharma S, Sehgal SC. Leptospirosis among schoolchildren of the Andaman and Nicobar Islands, India: Low levels of morbidity and mortality among pre-exposed children during an epidemic. Epidemiol Infect 2004;132:1115-20.

36. Karande S, Patil S, Kulkarni M, Joshi A, Bharadwaj R. Acute aseptic meningitis as the only presenting feature of Leptospirosis. Pediatr Infect Dis J 2005;24:390-1.

37. Fact sheet- Leptospirosis. World health Organization (Regional Office for South-East Asia). Available from: http://www.searo.who.int/ LinkFiles/CDS_leptospirosis-Fact_Sheet.pdf. [accessed on 2009 Jul 26].

38. Human leptospirosis: Guidance for diagnosis, surveillance and control. World Health Organization and International Leptospirosis Society. Available from: http://whqlibdoc.who.int/ hq/2003/WHO_CDS_CSR_EPH_2002.23.pdf. [accessed on $2009 \mathrm{Jul} 26$ ].

39. Sehgal SC. Recommendations of national symposium on leptospirosis. Indian J Med Microbiol 1997;15:211-2.

40. Karande S, Satam N, Kulkarni M, Bharadwaj R, Pol S. Leptospiral pneumonia. Indian J Pediatr 2005;72:e9-11.

41. Mathew $T$, Satishchandra $P$, Mahadevan A, Nagarathna S, Yasha TC, Chandramukhi A, et al. Neuroleptospirosis - revisited: Experience from a tertiary care neurological centre from south India. Indian J Med Res 2006;124:155-62.

42. Kobayashi Y. Human leptospirosis: Management and prognosis. J Postgrad Med 2005;51:201-4.

43. Senthilkumar TM, Subathra M, Phil M, Ramadass $P$, Ramaswamy V. Rapid serodiagnosis of leptospirosis by latex agglutination test and flow-through assay. Indian J Med Microbiol 2008;26:45-9.

44. Dey S, Madhan Mohan C, Ramadass P, Nachimuthu K. Diagnosis of leptospirosis by recombinant antigen based single serum dilution ELISA. Indian J Med Res 2008;128:172-7.

45. Cumberland $P$, Everard $C O$, Levett $P N$. Assessment of the efficacy of an IgM-Elisa and microscopic agglutination test (MAT) in the diagnosis of acute leptospirosis. Am J Trop Med Hyg 1999;61:731-4.

46. Velineni S, Asuthkar S, Umabala P, Lakshmi $V$, Sritharan M. Serological evaluation of leptospirosis in Hyderabad, Andhra Pradesh: A retrospective hospital-based study. Indian J Med Mircobiol 2007;25:24-7.

47. Vijayachari $P$, Sehgal SC. Recent advances in the laboratory diagnosis of leptospirosis and characterisation of leptospires. Indian J Med Microbiol 2006;24:320-2.

48. Hull-Jackson C, Glass MB, Ari MD, Bragg SL, Branch SL, Whittington CU, et al. Evaluation 
of a commercial latex agglutination assay for serological diagnosis of leptospirosis. J Clin Microbiol 2006;44:1853-5.

49. Mathur M, De A, Turbadkar D. Leptospirosis outbreak in 2005: LTMG hospital experience. Indian J Med Microbiol 2009;27:153-5.

50. Vinetz JM, Glass GE, Flexner CE, Mueller P, Kaslow DC. Sporadic urban leptospirosis. Ann Intern Med 1996;125:794-8.

51. Faucher JF, Hoen B, Estavoyer JM. The management of leptospirosis. Expert Opin Pharmacother 2004;5:819-27.

52. Wongsrichanalai C, Murray CK, Gray M, Miller RS, Mcdaniel P, Liao WJ, et al. Co-infection with malaria and leptospirosis. Am J Trop Med Hyg 2003;68:583-5.

53. Srinivas R, Agarwal R, Gupta D. Severe sepsis due to severe falciparum malaria and leptospirosis co-infection treated with activated protein $\mathrm{C}$. Malaria Journal 2007;6:42.

54. Kothari VM, Karnad DR, Bichile LS. Tropical infections in the ICU. J Assoc Physicians India 2006;54:291-8.

55. Singhsilarak T, Phongtananant $S$, Jenjittikul M, Watt G, Tangpakdee N, Popak N, et al. Possible acute coinfections in Thai malaria patients. Southeast Asian J Trop Med Public Health 2006;37:1-4.

56. Costa E, Lopes AA, Sacramento E, Costa YA, Matos ED, Lopes MB, et al. Penicillin at the late stage of leptospirosis: A randomized controlled trial. Rev Inst Med Trop S Paulo 2003;45:141-5.

57. Daher ED, Nogueira CB. Evaluation of penicillin therapy in patients with leptospirosis and acute renal failure. Rev Inst Med Trop S Paulo 2000;42:327-32.

58. Bal AM. Use of ciprofloxacin for treating leptospirosis-need for clinical trials. J Med Microbiol 2005;54:907.

59. Gonsalez CR, Casseb J, Monteiro FG, PaulaNeto JB, Fernandez RB, Silva MV, et al. Use of doxycycline for leptospirosis after high-risk exposure in São Paulo, Brazil. Rev Inst Med Trop Sao Paulo 1998;40:59-61.

60. Marotto PC, Marotto MS, Santos DL, Souza TN, Seguro AC. Outcome of leptospirosis in children. Am J Trop Med Hyg 1997;56:307-10.

61. Rajajee S, Shankar J, Dhattatri L. Pediatric presentations of leptospirosis. Indian J Pediatr 2002;69:851-3.

62. Daher E, Zanetta DM, Cavalcante MB, Abdulkader $\mathrm{RC}$. Risk factors for death and changing patterns in leptospirosis acute renal failure. Am J Trop Med Hyg 1999;61:630-4.

63. de Souza AL, Sztajnbok J, Marques SR, Seguro AC. Leptospirosis-induced meningitis and acute renal failure in a 19-month-old male child. J Med Microbiol 2006;55:795-7.

64. Lopes AA, Costa E, Costa YA, Sacramento E, de Oliveira AR Jr, Lopes MB, et al. Comparative study of the in-hospital case-fatality rate of leptospirosis between pediatric and adult patients of different age groups. Rev Inst Med Trop S Paulo 2004;46:19-24.

Source of Support: Nil. Conflict of Interest: None declared 